\title{
Elevation change measurements of the Greenland Ice Sheet
}

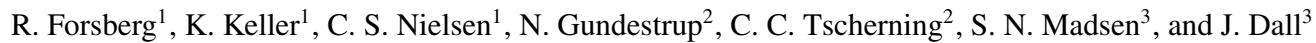 \\ ${ }^{1}$ Geodynamics Department, KMS, Rentemestervej 8, DK-2400 Copenhagen NV, Denmark \\ ${ }^{2}$ Geophysical Department, University of Copenhagen, Juliane Mariesvej 30, DK-2100 Copenhagen Ø, Denmark \\ ${ }^{3}$ Danish Centre for Remote Sensing, Technical University of Denmark, DK-2800 Lyngby, Denmark
}

(Received January 13, 2000; Revised July 13, 2000; Accepted July 14, 2000)

\begin{abstract}
Repeated GPS measurements have been performed at the centre of the Greenland Ice Sheet since 1992. Results have shown that the ice sheet is essentially stable at this location, with GPS-determined strain and elevation change rates in good accordance with yearly snow accumulation and glaciological flow models. In a local ice cap in East Greenland (Geikie Plateau) repeated GPS, airborne laser altimetry and SAR interferometry have been used to study ice movements in the more climatically variable coastal zone, where meter-level annual elevation changes are possible due to the high precipitation. The paper outlines the surveys carried out, some preliminary results, and intercomparisons of GPS, laser altimetry and SAR techniques.
\end{abstract}

\section{Introduction}

The elevation of the Greenland ice sheet represents a delicate balance between ice flow, firn compaction and precipitation. New snow accumulates at varying rates across the ice sheet and is eventually compacted into ice and transported to the edges of the ice sheet, where it either calves into the ocean as icebergs or melts/evaporates in the lower-level ablation zone. The heights of the ice sheet may be determined by numerous methods: GPS and surface surveys, satellite altimetry, airborne laser altimetry and airborne or satellite SAR interferometry. Each of the methods have different accuracy and effective footprint size, and the radar methods further have varying penetration into the firn.

This paper outlines results from some recent measurements of the ice sheet carried out as part of the ECOGIS project (Elevation Changes of the Greenland Ice Sheet), a cooperation between KMS, University of Copenhagen and the Danish Centre for Remote Sensing, Technical University of Denmark, supported by the Danish research council's TUPOLAR programme. In the ECOGIS project ice dynamics have been studied and methods compared in two areas at the centre of the ice sheet (around the GRIP and NGRIP drilling camps), as well as at a local, high-elevation coastal ice cap in East Greenland (Geikie Plateau) with a very large annual snow accumulation. At the latter site both airborne and satellite SAR interferometry have been tested, to investigate if SAR interferometry could be useful in studying height changes. The location of all ECOGIS field sites are shown in Fig. 1. In this paper we give results from GRIP, NGRIP and Geikie, only.

Copy right $(\mathrm{C}$ The Society of Geomagnetism and Earth, Planetary and Space Sciences (SGEPSS); The Seismological Society of Japan; The Volcanological Society of Japan; The Geodetic Society of Japan; The Japanese Society for Planetary Sciences.

\section{GPS Measurements at the Centre of the Ice Sheet}

The deep drilling sites of the GRIP and North GRIP (NGRIP) projects provided a logistical base for repeated GPS measurements. GRIP is located at the highest point of the Greenland ice sheet, and NGRIP approx. $300 \mathrm{~km} \mathrm{NNW} \mathrm{along}$ the main ice divide.

GPS measurements were done to the top of deep poles, frozen into the ice at $80 \mathrm{~m}$ depth. At GRIP (Fig. 2) the main pole was established in 1992 and at NGRIP in 1997. Yearly, week-long duration GPS surveys of the marker poles have been done, positioning the central pole relative to coastal bedrock points, primarily at Kangerlussuaq, located $1000 \mathrm{~km}$ away. The GPS observations have typically spanned a week, and have mainly been processed with Bernese software in ITRF-94 using IGS orbits. The accuracy of the determined ellipsoidal heights of the top of the pole is estimated to be below $10 \mathrm{~cm}$. However, some uncertainty resides in the results due to the large difference in heights from the coastal reference points, and thus uncertainty in the tropospheric correction (the ice sheet sites are located above $3000 \mathrm{~m}$ ).

In addition to the GPS top-of-pole heights the elevation of the snow surface is also measured. The accumulation of new snow, firn compaction and downward ice movement make the marker poles look like they are sinking at roughly $25 \mathrm{~cm}$ per year. The poles must therefore be regularly extended to prevent them from disappearing in the snow.

Results of the GPS and snow surface ellipsoidal height at GRIP, as well as the horizontal movements, are shown in Table 1 (NGRIP data are not finally processed). The table shows that the annual height change of the snow surface varies slightly, but overall it can be stated that the snow surface is in balance. There is thus no change of the height of the Greenland ice sheet at this particular point. The inferred short-term accumulation rates at GRIP are reasonably consistent with snow-pit data and longer-term core stratigraphy 
Table 1. Annual latitude, longitude and height change at GRIP deep pole ( $72^{\circ} 34^{\prime} 31^{\prime \prime} \mathrm{N}, 37^{\circ} 38^{\prime} 42^{\prime \prime} \mathrm{W}$, 1992 ellipsoidal snow surface height: $\left.3277.95 \mathrm{~m}\right)$.

\begin{tabular}{lcccc}
\hline GPS survey year ${ }^{1)}$ & $\begin{array}{c}\text { North change } \\
(\mathrm{cm})\end{array}$ & $\begin{array}{c}\text { East change } \\
(\mathrm{cm})\end{array}$ & $\begin{array}{c}\text { Pole height change } \\
(\mathrm{cm}, \text { pos. up })\end{array}$ & $\begin{array}{c}\text { Snow surface change } \\
(\mathrm{cm})\end{array}$ \\
\hline $1992-93$ & 7.4 & -24.0 & -28.7 & -10 \\
$1993-94$ & 12.1 & -16.7 & -22.0 & -9 \\
$1994-96$ & 9.2 & -25.7 & -19.5 & 12 \\
$1996-97$ & 12.5 & -30.7 & -30.7 & -2 \\
Yearly mean & 10.1 & -24.6 & -24.1 & 1 \\
\hline
\end{tabular}

1) 1995 data could not be processed due to excessive cycle slips.

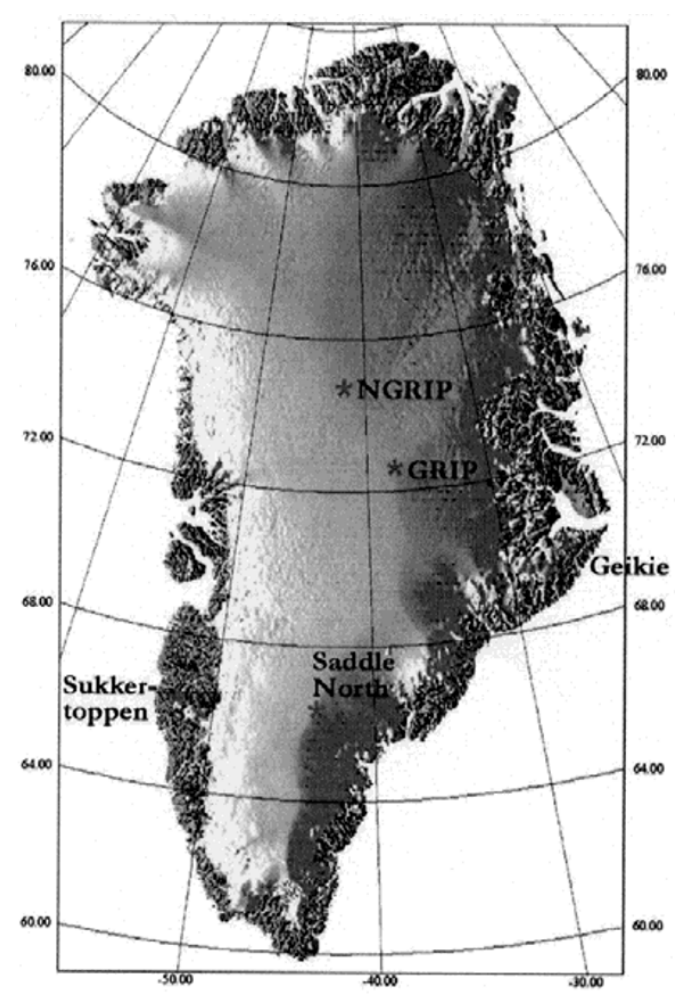

Fig. 1. Greenland ECOGIS field sites.

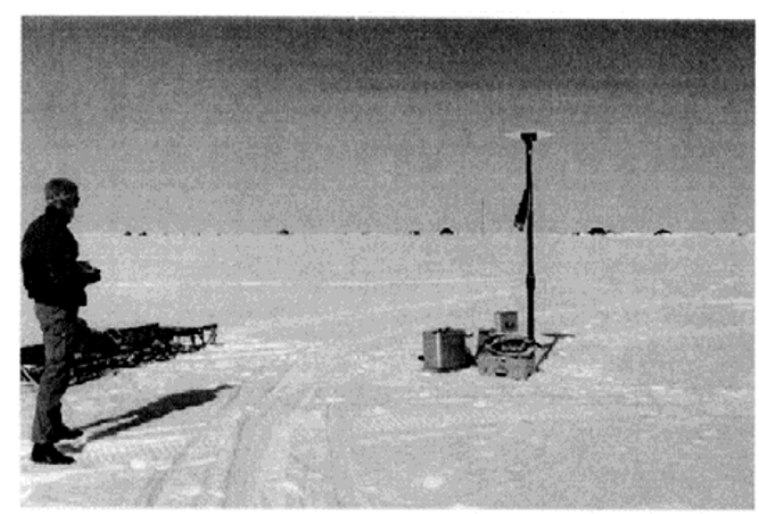

Fig. 2. GPS measurement at GRIP pole.

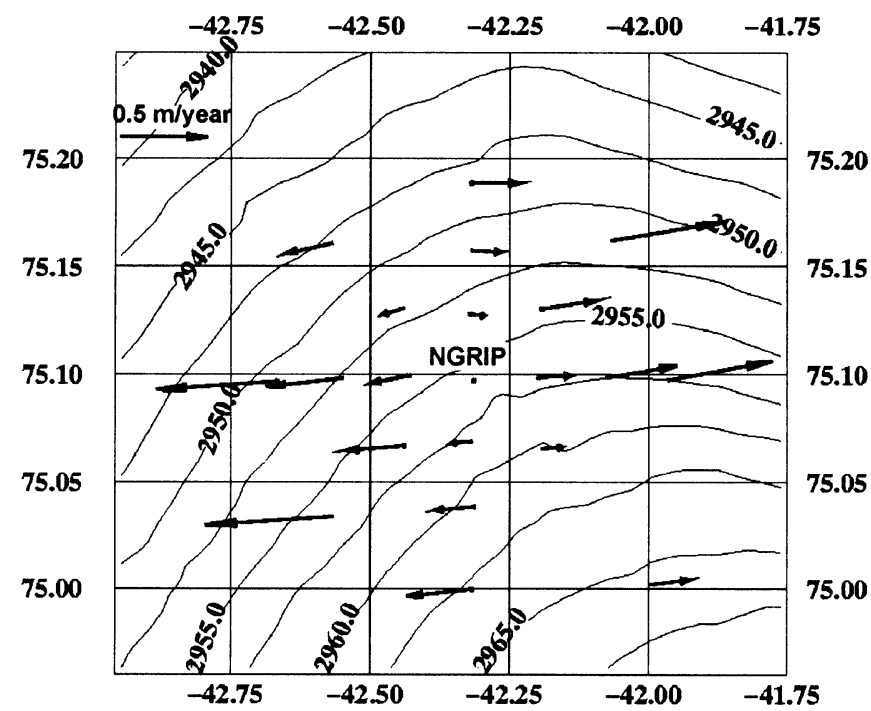

Fig. 3. Ice movements around NGRIP, relative to the deep central pole. Ice sheet elevations shown in meter.

estimates (Hvidberg et al., 1997; Bolzan and Strobel, 1994).

The overall ice dynamics at both GRIP and NGRIP have been studied by strain networks surrounding the central pole at different ranges up to $50 \mathrm{~km}$. These strain networks have been measured by GPS relative to the central pole, with yearly GPS sessions of a typical duration of $0.5-1 \mathrm{hr}$. Figure 3 shows an example of the strain rates around the NGRIP site, when the overall downslope ice movement along the ice divide has been taken out (i.e., the centrally determined horizontal ice velocity is used as reference).

The strain results at both GRIP and NGRIP show a very regular behavior, with velocites increasing outwards in good agreement with glaciological mass flow models, which indicates the present mass balance at GRIP to be $-3 \pm 4 \mathrm{~cm} / \mathrm{yr}$ (Hvidberg et al., 1997). The combined strain network results and glaciological modelling at GRIP therefore support the overall near-equilibrium results of the ice elevations.

Comparisons to satellite altimetry and active radar transponder measurements have been reported in HaardengPetersen et al. (1998). These results show that the satellite altimetry and GPS surface heights (including additional kinematic GPS traverses) are in reasonably good agreement (difference below $2 \mathrm{~m}$ ), and the surface reflection signal of 

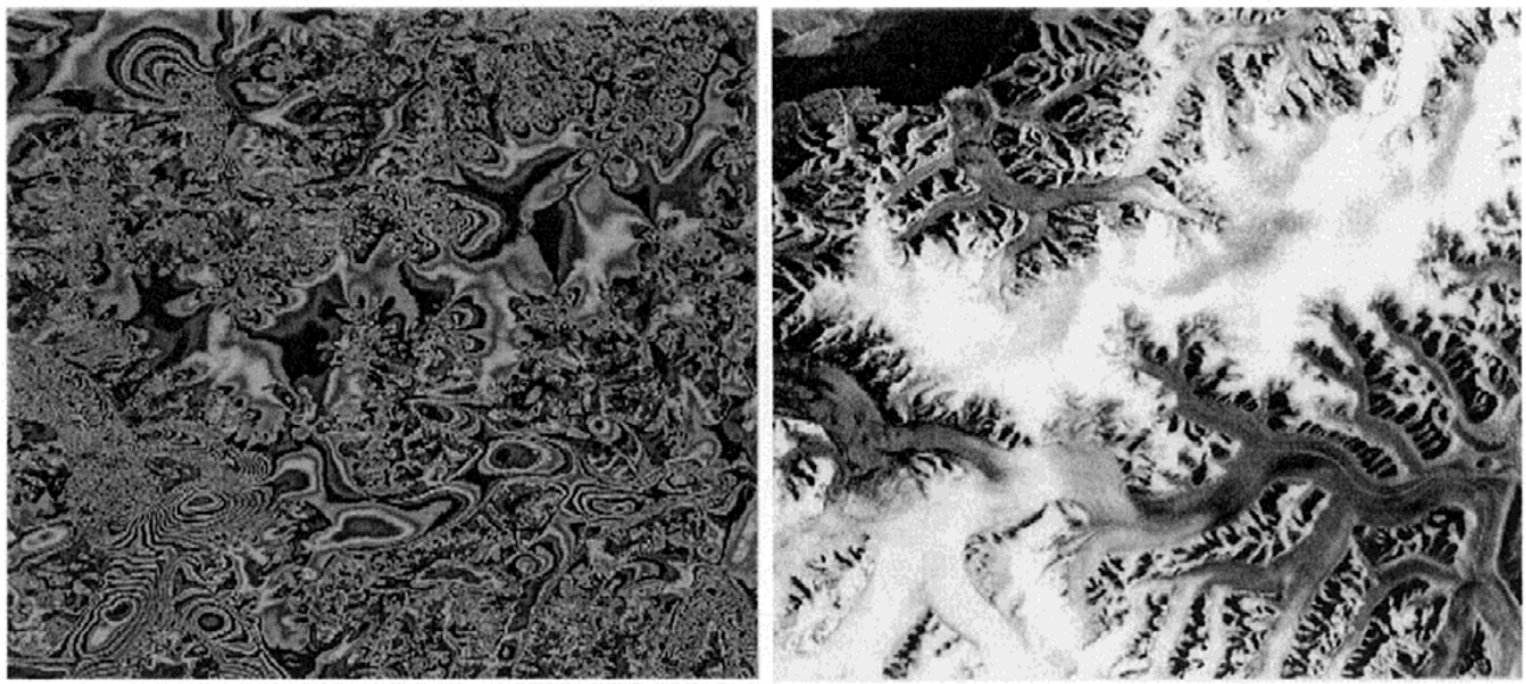

Fig. 4. SAR interferogram (left) and SAR amplitudes (right) over Geikie Ice Cap.

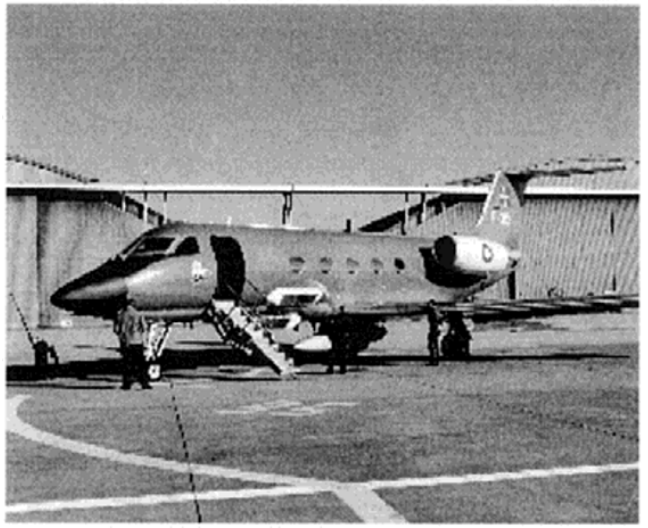

Fig. 5. G3 jet with SAR XTI antenna pair in front of wing.

the altimetry dominates over the volume scattering.

\section{GPS, Laser Altimetry and SAR Interferometry on the Geikie Ice Plateau}

The Geikie ice plateau is an elongated, narrow ice-dome, located at more than $2000 \mathrm{~m}$ elevation on top of the northern terminus of the steep tertiary basalt province just south of Scoresbysund. It is a region of extreme topography. It is also the poorest mapped part of Greenland.

The Geikie operations took place 1996-98, and included repeated GPS measurements at the assumed top of the plateau and four surrounding points, repeated mapping by airborne laser altimetry, and the positioning by GPS of corner reflectors for airborne SAR operations. In addition a shallow ice core was extracted and the subsurface bedrock mapped by ice radar (Lintz et al., 2000). Due to weather and logistical constraints not all repeated measurements were carried out as planned, and evaluation of results is still ongoing.

The Geikie ice cap shows relatively large changes in elevations due to the high yearly accumulation (3-4 m of snow). It is therefore a good target area to detect possible height changes by SAR interferometry. We have applied both satel-

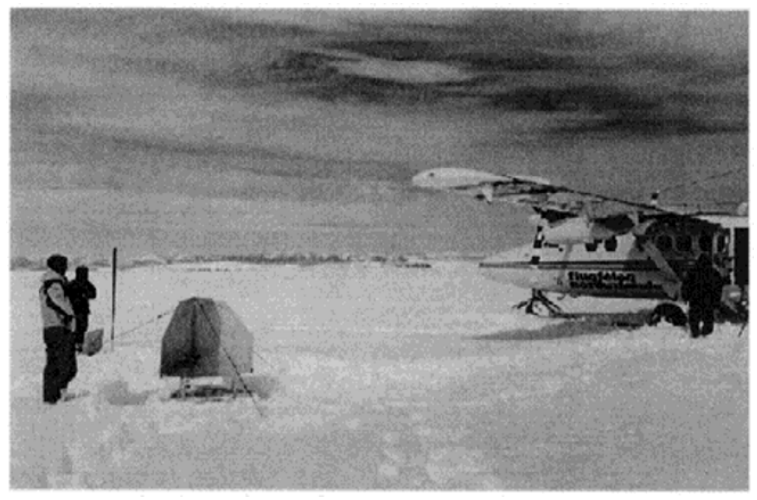

Fig. 6. Radar reflector on Geikie ice sheet.

lite and airborne SAR interferometry in the region, the latter primarily in order to compare velocities between SAR and repeated GPS observatations and to obtain a DEM, and the first to evaluate the accuracy of airborne SAR as a potential method to detect changes. Figure 4 shows an example of the ERS SAR amplitudes and interferograms over Geikie. A DEM of the area has been constructed from descending and ascending passes using the method of Mohr et al. (1997). The conversion of the SAR satellite data into heights and velocities is complicated significantly by the extreme topography (south of Geikie some valleys are flanked by up to $1000 \mathrm{~m}$ vertical walls), which produce radar shadows and layovers, and makes the unwrapping of interference fringes ambiguous.

Airborne SAR C-band interferometry has the advantage of higher accuracy and resolution, and by using dual antennas (cross-track interferometry, XTI) the uncertainties connected with ice movements disappear and radar interferogram fringes represent topography (and noise) only. Over Geikie both XTI and RTI (repeat track interferometry) was flown in 1997 and 1998 using the EMISAR system of the Danish Center for Remote Sensing (Madsen et al., 1996), 


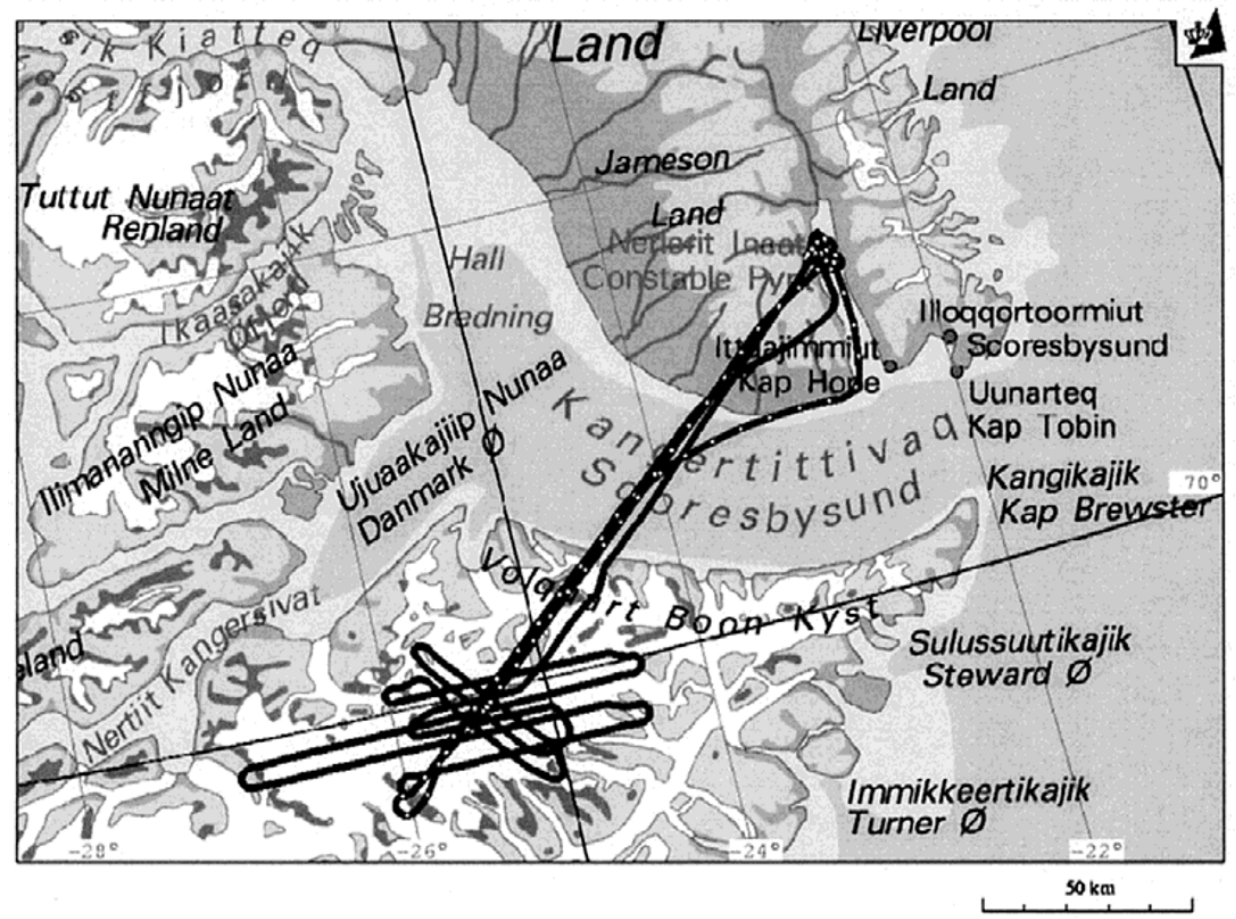

Fig. 7. Airborne laser altimetry tracks over Geikie Ice Cap (1996, two different flights shown).

mounted in a Gulfstream jet of the Danish Air Force. Radar reflector GPS positions were used to calibrate the airborne SAR data in the sense of fitting an overall bias in the elevations, but otherwise the corner reflector GPS coordinates were not used for SAR calibration. The SAR data were processed at DCRS in a $5 \mathrm{~m}$-resolution grid, subsequently averaged to $25 \mathrm{~m}$. At present only the XTI 1997 data have been processed.

The SAR data were evaluated primarily using airborne laser altimetry. An Optech laser altimeter was used in combination with kinematic GPS positioning and pitch/roll measurements to map the ice surface. Internal cross-over consistency of these measurements were at the $50 \mathrm{~cm} \mathrm{r.m.s.} \mathrm{level.}$ The main part of this error is probably due to kinematic GPS, as the reference GPS site used was more than $150 \mathrm{~km}$ away (at the airport of Constaple Pynt). A part of the error is due to insufficient roll and pitch, as a proper inertial measurement unit (IMU) was not available in 1996 (roll and pitch were derived from measured horizontal accelerometer measurements combined with GPS accelerations). In 1997 a prototype fibregyro IMU, manufactured by Greenwood Engineering, was used to obtain roll and pitch with higher accuracy. This allowed more safe constant-elevation flights than the 1996 flights, flown at a constant terrain clearance of 300 $\mathrm{ft}$ (nominally). A final source of cross-over error is the averaging applied (laser data were measured at 10 or $50 \mathrm{~Hz}$, subsequently averaged to $1 \mathrm{sec}$, corresponding to $60 \mathrm{~m}$ on the ground).

Since the laser-SAR DEM comparison is critically dependent on the correct processing of the kinematic GPS surveys, including sensor offsets, the airborne laser altimetry was checked by comparisons to overflights of the Constable Pynt runway. A dense geometric pattern of points was in- dependently established on the surface of the runway using a kinematic GPS survey by car. The runway comparison is shown in Table 2, and shows a good fit $(20 \mathrm{~cm})$, indicating no gross errors in the GPS processing. At the longer baseline lengths to Geikie the accuracy will degrade, however, but airborne GPS results should still be accurate well below half a metre or so.

The comparison between the laser altimetry in two successive summer surveys (1996 and 1997), as well as comparisons between laser altimetry and airborne SAR interferometry and ERS satellite tandem interferometry are additionally shown in Table 2. The laser internal cross-over errors are in part due to a large laser sampling interval (60 $\mathrm{m}$ on the ground). The laser intercomparison between 1996 and 1997 shows height changes on the order of $0.5-1 \mathrm{~m}$, which is in accordance with the general variations in the snowfall. The annual snow accumulation is $2-3 \mathrm{~m}$, as inferred from a shallow ice core taken in 1998. Overall the snow surface increased by roughly $0.5 \mathrm{~m}$ from 1996 to 1997, a number confirmed by static GPS measurements at the radar reflectors, and explained by a relatively large snowfall in the 1996-97 season.

The comparison to the airborne SAR interferometry shows that a $4.7 \mathrm{~m}$ r.m.s. agreement has been obtained, with a bias of $7 \mathrm{~m}$. The bias is mainly due to penetration effects of the radar signals into the ice sheet. The bias turns out to be height dependent, with shallow penetration (virtually no bias) below $1900 \mathrm{~m}$, and a $10 \mathrm{~m}$ bias above $2100 \mathrm{~m}$. This probably corresponds to the difference between the lowerelevation "wet snow" zone (also know as the "soaked snow" zone in glaciological snow facies terminology) and the upperelevation "percolation zone", where the firn contains a mix of refrozen ice lenses and dry snow, providing a larger degree of radar volume scattering and reflections from internal ice 
Table 2. Comparisons of laser altimetry and SAR interferometry at Geikie Ice Cap, East Greenland.

\begin{tabular}{lrr}
\hline \multicolumn{1}{c}{ Comparison (units: m) } & Mean & Std. dev. \\
\hline Airborne laser minus airport runway kinematic GPS & 0.16 & 0.25 \\
Internal accuracy of laser survey (1996; 87 cross-overs) & 0.02 & 0.63 \\
Internal accuracy of laser (1997; 130 cross-overs) & -0.01 & 0.65 \\
Laser altimetry 1997 minus 1996 (545 crossings) & 0.47 & 0.94 \\
Laser altimetry minus airborne SAR interferometry (1997) & 7.06 & 4.67 \\
Laser minus airborne SAR, above 2100 m only & 9.89 & 1.90 \\
Laser altimetry minus ERS satellite interferometry & -3.48 & 13.75 \\
\hline
\end{tabular}

layers. The Geikie ice cap is not high enough to display the "dry snow" zone facies typical of the interior of the Greenland ice sheet.

When restricting the SAR interferometry to the percolation zone, an r.m.s. fit of $1.9 \mathrm{~m}$ is obtained between laser and SAR, so at present airborne SAR interferometry may be assumed to be just barely useful for detecting climate-related height changes, but extremely useful for precise DEM determination for topographic mapping purposes. Satellite SAR interferometry is also useful to some degree for this purpose, showing a fit over Geikie of $14 \mathrm{~m}$ r.m.s. (the bias value is not significant, as the SAR DEM was fitted to the average level of the static GPS at the radar reflector elevations).

\section{Conclusions}

An extensive survey program has been carried out at the center of the Greenland ice sheet over a five year period. Our results show that the ice sheet is essentially in balance at this location, and there is a good agreement between GPS results, satellite altimetry and glaciological models for ice flow.

At the Geikie ice plateau in East Greenland, airborne and satellite SAR interferometry methods have been used to generate digital elevation models, mainly for an accuracy comparison test. Satellite SAR intereferometry showed an accuracy around $15 \mathrm{~m}$ r.m.s., and airborne SAR interferometry accuracies down to $2 \mathrm{~m}$ r.m.s. when compared to indepen- dent GPS and laser data in the wet snow or percolation snow facies zones. In the latter high elevation zone the airborne SAR interferometry shows a strong $10 \mathrm{~m}$ height bias, probably due to significant volume scattering of the C-band radar signals.

\section{References}

Bolzan, J. F. and M. Strobel, Accumulation rate variations around Summit, Greenland, Journal of Glaciology, 40(134), 56-66, 1994.

Haardeng-Petersen, G., K. Keller, C. C. Tscherning, and N. Gundestrup, Modeling the signature of a transponder in altimeter return data and determination of the reflection surface of the ice cap near the GRIP camp, Greenland, Journal of Glaciology, 44(148), 625-633. 1998.

Hvidberg, C. S., K. Keller, N. S. Gundestrup, C. C. Tscherning, and R. Forsberg, Mass balance and surface movement of the Greenland Ice Sheet at Summit, Central Greenland, Geophys. Res. Lett., 24(18), 2307-2310, 1997.

Lintz, E., N. Reeh, R. Forsberg, J. H. Jørgensen, N. Skou, and K. Woelders, A low cost glacier mapping system, Accepted for publication, Journal of Glaciology, 2000 (in press).

Madsen, S. N., N. Skou, J. Granholm, K. Woelders, and E. L. Christensen, A system for airborne SAR interferometry, Int. J. of Electronics and Communications, 50(2), 106-111, 1996.

Mohr, J., S. N. Madsen, and N. Reeh, ERS tandem study of glacier dynamics in NE Greenland, Proc. 3rd ERS symp. on space at the service of our environment, ESA SP-414, pp. 989-993, 1997.

R. Forsberg (e-mail: rf $@$ kms.dk), K. Keller, C. S. Nielsen, N. Gundestrup, C. C. Tscherning, S. N. Madsen, and J. Dall 